\title{
"VOCÊ DEIXARIA SUA FILHA SE CASAR COM UM NEGRO"? ALGUMAS CONSIDERAÇÕES SOBRE A AMBIGÜIDADE NAS QUESTÕES DE PESQUISA.
}

Fernando Lefèvre *

Resumo: Discute-se, neste trabalho, a questão da ambigüidade na pesquisa social e na pesquisa social em saúde, que está quase sempre presente nas perguntas dos pesquisadores e nas respostas dos pesquisados. llustra-se 0 problema com a discussão dos pressupostos e das dúvidas presentes na conhecida questão: "Você deixaria sua filha se casar com um negro?" Concluise pela necessidade, na pesquisa social e na pesquisa social em saúde, de se formular questões preferencialmente abertas, com enunciados não ou pouco ambíguos, que possam dar margem à expressão, pelos respondentes, de opiniões ou representações sob a forma de discursos ou cadeias argumentativas. Os discursos ou cadeias argumentativas tem a dupla vantagem de apresentarem mais material verbal, o que diminui a probabilidade da ocorrência de ambigüidade nas respostas, e de serem formas mais adequadas à expressão do pensamento.

\section{INTRODUÇÃO}

Quando, numa pesquisa - sobretudo, mas não exclusivamente, na pesquisa social e, certamente, no campo da Saúde Pública - no momento da elaboração de um questionário ou formulário, concebe-se uma questão, é condição obrigatória que o enunciado da questão não sofra de ambigüidade ${ }^{1}$.

\footnotetext{
* Prof. Dr. da Faculdade de Saúde Pública da USP
} 
É evidente que só é possivel somar um "concordo", ou um "sim", ou um "não" com outro quando eles estiverem significando a mesma coisa ou coisas muito próximas como respostas eliciadas por um enunciado de questão não ambiguo ou pouco ambiguo.

Quase sempre, porém, em todos os campos do conhecimento (e, certamente, no campo da saúde em seus aspectos sociais), afora certas situações muito precisas, as perguntas padecem de algum grau de ambigüidade.

Por isso, como advogamos mais detalhadamente a seguir, o "pensar" dos individuos sobre um tema qualquer (e certamente sobre temas ligados à saúde) deve, preferencialmente, ser resgatado através de questōes "abertas" ${ }^{5}$, formuladas em termos gerais, destituído de ambigüidade, para se evitar que se somem, por exemplo duas respostas "sim" que correspondam a representaçōes ${ }^{6}$ ou opiniōes distintas. Enfim, é preciso que não haja dúvida sobre aquilo que se está perguntando para que não haja dúvida sobre aquilo que se está respondendo.

Afim de ilustrar um aspecto desta problemática discorreremos, a seguir, sobre a conhecida questão: "Vocé deixaria sua filha se casar com um negro?", imaginada como uma questão fechada, comportando alternativas de resposta "sim", "não" e "talvez" e vista como um bom exemplo, segundo pensamos, de questão ambigua, prenhe de pressupostos e dúvidas. 


\section{ANÁLISE DA QUESTÃO: "VOCÊ DEIXARIA SUA FILHA SE}

\section{CASAR COM UM NEGRO?"}

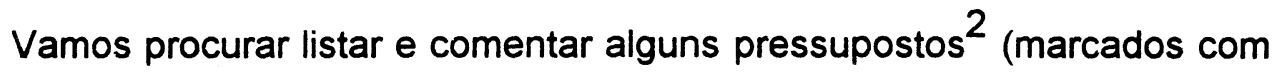
um ponto final) e algumas interrogações ou dúvidas (marcadas com um sinal de interrogação) subjacentes na questão acima.

1) sobre o quê e sobre quem está respondendo o depoente? Sobre sua filha real ou sobre uma filha imaginária (no caso do respondente não ter filhos ou não ter filha)?

2) toda filha deve, necessariamente, se casar.

3) o que é casar? Inclui amigar-se?

4) para casar é, sempre, necessário pedir permissão aos pais.

5) o disposto em "4" só se aplica às filhas mulheres e não aos filhos homens.

6) todo negro é igual; ou todo negro é somente negro e não negro pobre, rico, feio, bonito, etc.

7) não existem filhas homossexuais, que não desejam se casar com homens.

8) o que significa "não deixar casar", no caso do depoente ter respondido não à questão? Significa impedir, por todos os meios? Significa tentar impedir? 
9) deixar ou não a filha casar com um negro é uma situação extrema, aguda, em relação ao racismo, que pode discriminar os (pais) aparentemente liberais dos verdadeiramente liberais.

Em face disto e a bem da lógica e da ética, a pergunta em questão deveria ser precedida de todos os seus pressupostos e todas as dúvidas deveriam estar resolvidas na sua formulação. Além disso, evidentemente, o entrevistado deveria se posicionar diante dos pressupostos explicitados.

O que acontece quando uma questão do tipo da analisada acima, contém dúvidas e pressupostos?

Quanto às dúvidas, é claro que elas dão margem a ambigüidade porque um respondente pode interpretar de um modo a expressão lingüistica contida na questão e outro respondente de modo diverso.

Quanto aos pressupostos, problema complexo examinado por filósofos da linguagem como DUCROT ${ }^{2}$ entre outros, a ambigüidade, a despeito de ser mais difícil de ser demonstrada, também permanece, como procuraremos mostrar a seguir.

Examinemos, para este fim, como exemplo, um dos pressupostos contidos na nossa questão, qual seja, o pressuposto de que "todas as filhas devem pedir permissão para os pais para se casar". Tornado explicito este pressuposto emerge a ambigüidade porque deveríamos ter duas e não apenas uma questão, ou seja :

1) "todas as filhas devem pedir permissão aos pais para se casar?" e (caso a resposta seja "sim"),

2) "você deixaria sua filha casar com um negro?" 
Com tudo o que foi dito até agora estamos sugerindo que perguntas aparentemente simples como a que estamos discutindo podem esconder um "iceberg" de ambigüidade.

É claro que a ambigüidade não é privilégio de qualquer área; é também claro que a da Saúde, pelos evidentes aspectos humanos que envolve, está certamente sujeita a este tipo de problemas epistemológicos e metodológicos.

Apenas para exemplificar, imaginemos uma questão fechada bastante simples e banal, envolvendo a problemática (atual) das pesquisas sobre satisfação do usuário dos serviços de saúde.

Questão:

O tempo de espera para o atendimento médico neste Posto de Saúde é:

- longo

- curto

- adequado

Trata-se de uma questão ambigua já que a cada uma destas alternativas, consideradas em si mesmo, é bastante provável que correspondam quantidades distintas de tempo real, caso comparemos, por exemplo, usuários de classe média, recentemente incorporados ao sistema público de saúde, com usuários "tradicionais" deste sistema. Para os primeiros, que têm o atendimento privado/liberal como parâmetro, 2 horas de espera, por exemplo, podem significar um tempo longo, enquanto que para os últimos podem estar significando um tempo razoável. 
Além do mais, ainda neste exemplo, mesmo considerando um único tipo social de usuário, tempos numericamente equivalentes de espera podem ser diferentemente avaliados em função das condições de momento do cliente: é claro que esperar 2 horas em uma situação vivida como emergencial ou incômoda não tem o mesmo valor (em termos de satisfação) do que esperar 2 horas em uma situação vivida como normal.

Evidentemente, não há questão que envolva opiniões, atitudes, representações, sobre qualquer tema, que não contenha mais ou menos pressupostos e dúvidas e que, portanto, não esteja eivada de ambigüidade; entretanto, os pressupostos e as dúvidas, e a consequente ambigüidade delas derivada, a despeito de não poderem ser totalmente eliminadas, devem ser reduzidas ao mínimo sob pena de estarmos comparando respostas sobre uma questão que só aparentemente é a mesma.

Segundo pensamos, as questões abertas permitem minorar o problema da ambigüidade, por algumas razões que expomos a seguir:

\section{A PERTINÊNCIA DISCURSIVA}

A primeira destas razões é que a questão aberta dá nascimento a um discurso e o pensamento dos indivíduos, que expressa as suas opiniōes ou representações ${ }^{6}$ relativas a temas de uma área, se coaduna mais com a forma discursiva do que com outras formas. Ou seja, consegue-se chegar tendencialmente mais próximo da verdade (ou mais distante da ambigüidade) deste pensamento e da representação que ele carrega quando este e esta são acessados através de um discurso do que quando o acesso se dá através de um mero "concordo" (ou "concordo muito"), ou "sim" ou "não". 
Quando dois entrevistados respondem "não" à questão que estamos analisando chega-se à conclusão que eles pensam do mesmo modo (que ambos são racistas) simplesmente porque ambos emitem a mesma palavra "não", que é interpretada como capaz de expressar fiel e sinteticamente o pensamento destes individuos sobre o tema do racismo.

Ora, isto não é necessariamente verdade porque os indivíduos, em geral, pensam "por", ou "através" da forma discursiva ${ }^{7}$ e não por meio de expressōes sintéticas do tipo "sim", "concordo" etc., que, por permitirem mais facilmente a quantificação, acabaram se impondo na pesquisa social por razões históricas ligadas a supostos paradigmas de cientificidade, importados das chamadas "verdadeiras" ciências (biologia, física, etc.) 3,8

Os individuos que tem algo a dizer sobre um dado tema, em geral, expressam-se através de um discurso porque este "algo a dizer", este "pensar sobre" é uma argumentação (de boa ou má qualidade, não importa), ou seja, uma sucessão articulada de frases, ou seja um discurso. Só é possível, então, segundo pensamos, conhecer, de fato, o pensamento destes indivíduos conhecendo seus discursos.

\section{O DISCURSO COMO REDUTOR DA AMBIGÜIDADE}

\section{NAS PERGUNTAS E RESPOSTAS.}

Pode-se dizer, creio, no relativo à pesquisa social, que se está fazendo ciêrıcia ou produzindo conhecimento quando, entre outras coisas, se consegue mostrar ou juntar evidências que tornem plausivel ${ }^{3,4}$ dizer que um conjunto de respondentes está afirmando a mesma coisa (ou coisa semelhante) sobre um mesmo tema. 
É evidente que não basta aplicar um mesmo questionário ou formulário a uma dada população para que se tenha, automaticamente, um conjunto de respostas sobre um mesmo tema, porque, como mostra o exemplo da questão fechada sobre o negro, um respondente, por exemplo, pode estar pensando num certo tipo de negro (o negro pobre, inculto, analfabeto) e outro em qualquer tipo de negro; da mesma forma, um respondente pode estar entendendo o "não deixar" da questão como impedimento total e outro como impedimento relativo ("eu não deixaria minha filha casar com um negro mas ela casaria assim mesmo"). Ora, se há entendimento divergente sobre o tema da questão, os respondentes não estão respondendo sobre o mesmo tema apesar de estarem respondendo à mesma questão.

Portanto, há que fazer um esforço para reduzir ou minimizar a ambigüidade tanto em nivel da questão de pesquisa quanto em nivel da resposta.

Com efeito, é preciso que fique claro não apenas se os respondentes estão respondendo ao mesmo tema (questão) mas também como estão se posicionando diante deste mesmo tema (resposta).

Ora, para investigar e interpretar este "como" é também necessário eliminar ou diminuir a ambigüidade nas respostas, o que é muito mais provável de ocorrer se estas forem discursos e não meras palavras ou expressões sintéticas como "sim", "concordo" etc. Isto por uma razão que poderíamos chamar de quantitativa: na pesquisa social é importante propiciar o surgimento (através de instrumentos abertos de pesquisa) ${ }^{3,4}$ de respostas discursivas, não apenas porque, como se assinalou acima, as pessoas pensam discursivamente, de modo argumentado, mas também porque através dos discursos, que são quantidades maiores de material verbal, é possível, em princípio, saber com mais objetividade e certeza (ou com menos ambigüidade) aquilo que efetivamente os individuos 
pensam a respeito de um dado tema. Isto, aliás, é algo que todo psicólogo experiente sabe: quando quer obter um depoimento verdadeiro do analisado uma das técnicas de que lança mão é fazê-lo falar mais e mais discursivamente (ou seja, menos monossilabicamente) sobre o tema porque isto aumenta a possibilidade da verdade vir à tona (ou ao consciente).

\section{CONCLUSÃO}

O importante, é claro, quando se trata de pesquisa social e, certamente, de pesquisa social em saúde, não é parecer objetivo, mas efetivamente sê-lo; o que tem a ver, tanto na pesquisa dita qualitativa quanto na dita quantitativa ${ }^{4}$, com somas ou agregações que dão nascimento a agrupamentos, conjuntos, classes de representações, de opiniões e, portanto, necessariamente, com sentidos o mais que possivel univocos, não ambíguos.

É claro, também, que a ambigüidade deve estar ausente ou minimizada tanto nas questões quanto nas respostas e tanto nas questões fechadas quanto nas abertas. Uma questão aberta propicia o surgimento de discursos, de cadeias argumentativas, o que, como se disse, é desejável porque pensar, em seu sentido "natural", espontâneo, é discursar, argumentar e porque é menos provável ser ambiguo quando se "discursa" do que quando se "concorda" ou "discorda". Mas não basta que a questão seja aberta, ela precisa também ser não ambígua, porque se não for o caso, os respondentes estarão discursando, argumentando, sobre temas talvez distintos o que, obviamente, tornará estes discursos não comparáveis e a pesquisa destituida de valor.

Um último aspecto a destacar, referente a interpretação dos discursos. 
Os discursos, para que possam dar margem a um conhecimento ou interpretação do pensar de grupos de individuos, podem e devem ser agrupados sob categorias ou rubricas que os unifiquem; mas esta não é tarefa fácil e, ademais, numa larga medida, depende da intuição e da história de vida do pesquisador (para não dizer da sua inteligência, ou do seu "capital cultural"), sem que seja, necessariamente possivel e mesmo desejável, fixarem-se procedimentos formais e padronizados (como, por exemplo, a presença nos discursos de uma mesma palavra) para 0 ato de categorizar. Mesmo porque dois pesquisadores podem, legitimamente, propor, para uma mesma massa de discursos, agrupamentos distintos, com base em critérios distintos de categorização, que não divirjam mas que se somem, aumentando (e não diminuindo) a cientificidade do conhecimento sobre o tema.

Enfim, as questões abertas não ambiguas e os discursos delas decorrentes diminuem a probabilidade de ocorrência da ambigüidade mas são mais complicados ou incômodos. Por isso muitos pesquisadores o temem e o evitam. É verdade que os discursos solicitam mais do pesquisador, requerendo mais ousadia destes. Mas, também em pesquisa, "quem não arrisca...".

\section{REFERÊNCIAS BIBLIOGRÁFICAS}

1. COSTA LIMA, L. et al. Dicionário básico de comunicação. Rio de Janeiro, Paz e Terra, 1975.

2. DUCROT, O. Dire et ne pas dire. Paris, Herman, 1972.

3. GATTI, B. A. Conferência sobre pesquisa qualitativa. São Paulo, Faculdade de Saúde Pública da USP, 1990.

4. MINAYO, M. C. S. O desafio do conhecimento: metodologia de pesquisa qualitativa em saúde. São Paulo/Rio de Janeiro, Hucitec/Abrasco, 1992. 
5. SILVA, M. E. L. Entrevista aberta. FSP/USP, 1985. (mimeo)

6. SPINK, M. J. P. O conceito de representação social na abordagem psicossocial Cad. Saúde Pública, 9: 300-8, 1993.

7. VERON, E. A produção do sentido. São Paulo, Cultrix/Edusp; 1980. 